\title{
AN UPDATE ON HAPPENINGS AT THE GDC
}

Chief Executive and Registrar of the General Dental Council Evlynne Gilvarry is to step down in January.

Having led the GDC for over five years as its Chief Executive and Registrar, Ms Gilvarry has decided to leave the organisation with effect from next year. She will continue in her role until the end of January 2016. An interim Chief Executive and Registrar will be sought following her departure.

New powers enabling long-awaited changes to the way the GDC carries out their fitness-to-practise (FtP) proceedings have been announced by the Department of Health. The new powers, set out in legislation laid in Parliament, are designed to improve the efficiency of the fitness to practise processes, enabling swifter investigation of complaints which will improve the system for both patients and dental professionals.

Under the new arrangements, due to come into effect in April 2016, the GDC will be able to appoint case examiners with powers to decide cases at an earlier stage than at present.

The GDC has also published its second annual review of the quality of dental training in the UK.

During 2013/14, 17 education and training programmes were inspected to make sure they meet the standards of education so that new entrants to the dental profession can demonstrate the required learning outcomes to enter the Dentists or DCP Registers.

The review found students were properly assessed to make sure they had the right skills and knowledge before treating patients, knew how to obtain valid consent and how to raise concerns appropriately.

Commenting on the review Evlynne Gilvarry said: 'Our annual review shows that the majority of programmes are providing training which meets the standards that we have set. The overall performance of dental schools and DCP training providers is good and ensures that new graduates are equipped with a core set of skills to be registered with the GDC and to start their dental careers with confidence.'

\section{CAN YOU HELP WEST MERCIA POLICE?}

West Mercia Police have launched a murder investigation following the discovery of skeletal remains of a man close to the M54 motorway in Telford, Shropshire.

The investigation team is seeking help from people in the dental community who may be able to assist in identifying this male.

The male is believed to be between 5'7" and 5'11" tall and aged between 30 and 49 at the time of his death. The images below depict specific dental work and show different
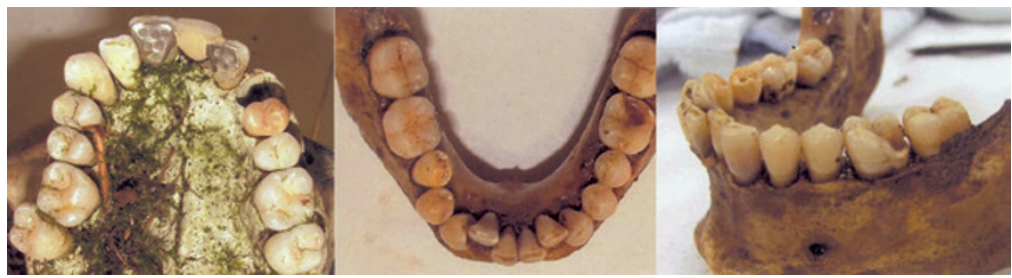

\section{BOOK REVIEW}

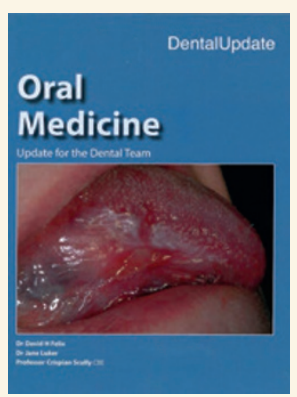

ORAL MEDICINE: UPDATE FOR THE DENTAL TEAM

David H. Felix, Jane Luker and

Crispian Scully

George Warman Publications

Ltd in association with Stephen

Hancocks Ltd

price £39.99 pp 146

ISBN 9780993228001

Oral medicine: Update for the dental team is the first of three books to be launched by Dental Update from their authors in 2015. This is a new title in the Dental Update Books series, which aims to provide a concise, practice friendly chairside companion for the dental team. This specific volume helps to identify and diagnose oral conditions and lesions, as well as providing advice on treatment and making appropriate referrals.

Divided into 17 chapters, the work is based on a recent series of articles in Dental Update. There are multiple chapters which focus on ulceration, lumps and swellings, and radiolucencies and radio-opacities; whilst individual chapters concern halitosis, white lesions, red and pigmented lesions, orofacial sensation and movement and orofacial pain. The authors have many years of experience in the various subjects and aptly apply their knowledge in a practical and succinct style. They have approached the subject mainly via the symptomatic approach, as it largely relates to the presenting complaint, which they considered to be more helpful for general dental practitioners, rather than taking a diagnostic category approach. The clinical aspects of the relevant disorders are discussed, including a brief overview of the aetiology, detail on the clinical features and how the diagnosis is made. There is guidance on management and when to refer, as well as relevant websites which offer further detail on the subjects. Accompanying clinical photographs of conditions are of high quality and comprehensive tables demonstrate the causes of oral conditions. These are presented in a logical order for the reader, leading them through each condition effectively.

The target audience of this book, based on the style and approach of the work, is most likely a busy general dental practitioner, as an effective and useful chair-side reference. The clinical photographs and tables highlighting causes of oral conditions are likely to prove an excellent aide-memoire when revising for examinations, making it a perfect go-to for the undergraduate dental student. The information in the book could also be helpful to the whole healthcare team, as dental education is considered to be lacking for doctors, nurses and pharmacists who may be called upon to advise on oral issues. To conclude, all practice teams, dental and medical, will find this easy-to-use reference book invaluable.

R. SMYTH 